\title{
Illusion decrement in wings-in and wings-out Müller-Lyer figures
}

\author{
MARIA WATSON \\ Duke University, Durham, North Carolina \\ SUZANNE GREIST-BOUSQUET \\ Kean College of New Jersey, Union, New Jersey \\ and \\ H. R. SCHIFFMAN \\ Rutgers, The State University, New Brunswick, New Jersey
}

\begin{abstract}
Illusion decrement with inspection was assessed separately for wings-in and wings-out MüllerLyer figures. Subjects reproduced the central extent in Müller-Lyer figures under three conditions: the subjects in Experiment 1 made responses at 1-min intervals during a 5-min inspection period, the subjects in Experiment 2 made responses at 1-min intervals without inspection between judgments, and Experiment 3 provided the subjects with implicit feedback during inspection. Separate inspection of wings-in and wings-out figures produced similar decrement effects. Illusion decrement was observed in Experiment 1, but the decrement was comparable to the control condition of repeated judgments without intervening inspection (Experiment 2). When provided with implicit feedback during inspection (Experiment 3), pronounced illusion decrement was obtained, but not for all subjects. The variability associated with responses in all experiments was high, and a large percentage of subjects did not show illusion decrement after 5 min of inspection. Thus, general and firm conclusions concerning reliable illusion decrement are unwarranted.
\end{abstract}

Visual geometric illusions and their associated phenomena have been examined by visual scientists for over a century. The consistent, systematic errors associated with visual geometric illusions have been explained on the basis of structural mechanisms and cognitive mechanisms (e.g., Girgus \& Coren, 1973). Structural mechanisms include the properties of the optical and neural systems that effect consistent errors, whereas cognitive mechanisms include the error-producing recalibration strategies that humans use to encode, interpret, and process visual information.

A possible technique for assessing the relative contributions of structural and cognitive mechanisms is the measurement of illusion decrement with prolonged inspection. For example, the magnitude of the Müller-Lyer illusion and several of its variations decreases with continued inspection, yet the illusion does not entirely disappear (Coren \& Girgus, 1972; Girgus \& Coren, 1973; Girgus, Coren, \& Horowitz, 1973). Coren and his colleagues argue that the decrement associated with such continued inspection reflects the amount of cognitive involvement in a visual illusion; the magnitude of the illusion that remains after inspection reflects the degree of structural involvement in promoting error. Accordingly, an illusion

This research was supported by funds from the Research Council of Rutgers, The State University to the third author. Correspondence should be addressed to Suzanne Greist-Bousquet, Department of Psychology, Kean College of New Jersey, Union, NJ 07083. that is purely structurally caused would be expected to show no decrement with inspection, whereas an illusion that is purely cognitively caused would be expected to decrease to zero.

Thus, it is possible to assess the anatomy of a specific geometric illusion by estimating the relative involvement of structural and cognitive components. Moreover, this information might then determine whether or not two illusions share a similar basis. There is evidence, for example, that the wings-in and wings-out Müller-Lyer illusions may be differentially promoted by structural and cognitive components (Greist-Bousquet \& Schiffman, 1981). Further verification that the wings-in and wingsout versions of the Müller-Lyer are indeed different illusions might arise from evidence that the two versions decrease at different rates with inspection, as this would imply that the contributing factors are present in different proportions. Accordingly, in the present set of studies, illusion decrement was examined separately for wings-in and wings-out Müller-Lyer figures.

By examining illusion decrement separately for wingsin and wings-out Müller-Lyer figures, another issue emerges. This issue concerns the conditions under which illusion decrement is obtained with inspection. Previous studies of illusion decrement with inspection of the Müller-Lyer figure have used the Brentano (or combined) version of the illusion (e.g., Coren \& Girgus, 1972; Day, 1962; Festinger, White, \& Allyn, 1968; Girgus \& Coren, 1973; Girgus, Coren, \& Horowitz, 1973; Kohler \& Fish- 
back, 1950; Porac \& Coren, 1985) in which both wingsin and wings-out elements are present for comparison. However, Day (1962) reported that illusion decrement with inspection of the Brentano version of the Müller-Lyer figure depends upon conditions that permit the subject to compare the wings-in and wings-out elements. Indeed, comparison of the figural components appears vital for illusion decrement: Decrement does not occur if the figure is fixated during inspection (Day, 1962; Festinger, White, \& Allyn, 1968) or if the figure is presented tachistoscopically (Kohler \& Fishback, 1950). If comparison of the elements of the figure cannot occur, as with separate presentations of the wings-in and wings-out Müller-Lyer figures, will illusion decrement occur? The following experiments address this question.

\section{EXPERIMENT 1}

\section{Method}

Subjects. Fifty-four undergraduate students served as subjects. All had corrected or uncorrected 20/20 vision.

Stimuli. Series of the standard Müller-Lyer figures, each composed of a shaft and attached wings, were reproduced on $21.6 \times 27.9 \mathrm{~cm}$ sheets of white paper.

The components of the line figures were constructed from 0.4-mmwide black graphic tape. The lengths of the shafts of the stimulus figures were constant at $60 \mathrm{~mm}$. The wings of the figures were $10 \mathrm{~mm}$ long and formed a $45^{\circ}$ angle with the shaft in the wings-in figure and a $135^{\circ}$ angle with the shaft in the wings-out figure.

The stimulus figures appeared in the center of the left half of the stimulus sheet. A $90-\mathrm{mm}$-long response line was centered in the right half of the stimulus sheet.

Inspection figures of both versions of the Müller-Lyer figure were prepared. Their measurements were identical to those of the stimulus figure, and they were also centered in the left half of the sheet; however, the response line was deleted.

\section{Procedure}

Twenty-seven subjects inspected and made judgments on the wingsin figure; 27 subjects inspected and judged the wings-out figure. Each subject was presented first with a stimulus sheet in such a way that its long side was parallel to the table's edge. The subjects were instructed to indicate their estimate of the length of the shaft by placing a slash through the response line such that the length marked off matched the central linear extent contained in the stimulus figure. The leftmost point of the response line was indicated as the starting point. The subject was allowed to reposition his or her response, but measurements against the pencil or fingers were not permitted. After the subject's response, the stimulus sheet was turned face down, and the subject was presented with an inspection sheet. Each subject was instructed to move his or her eyes back and forth across the figure throughout the 60-sec inspection period. Close monitoring by the experimenter ensured that these instructions were followed. Stimulus and inspection sheets were interleaved such that each subject studied the figure a total of $5 \mathrm{~min}$ and made a total of six responses.

\section{Results and Discussion}

The extent produced by the subject on the response line was measured to the nearest $0.5 \mathrm{~mm}$. To compare rates of illusion decrement for the two figures, any change associated with judgments on wings-in figures required placement on the same scale as the change associated with judgments on wings-out figures. This was accomplished by converting each judgment to a value of absolute illusion magnitude. Specifically, each judgment was sub- tracted from the true extent of the shaft for the wings-in figures, and the true extent was subtracted from the judgment for the wings-out figures. (The translation to measures of absolute magnitude changes the typical underestimation observed for the wings-in figure to positive values. Negative numbers occur only with a reversal of typical effects-i.e., if underestimation is observed for the wings-out illusion or if overestimation is observed for the wings-in illusion.) The mean absolute magnitude of the illusion for each of the six judgments is plotted in Figure 1 for each figure. The data from this experiment are identified by the number 1 in the figure.

Homogeneity of variance was verified statistically, and an analysis of variance was performed on these data with illusion figure as the between-subject factor and judgments as a within-subjects factor. A significant difference was found between the wings-in and wings-out Müller-Lyer illusions $[F(1,52)=11.169, p<.05]$. A significant decrement effect was found $[F(5,260)=2.670, p<.05]$. The interaction was not significant $[F(5,260)=.733$, $p>$.05]. These findings indicate that the wings-in and wings-out illusions decrease at similar rates. The present findings also show that illusion decrement occurs with separate inspection of the figures even in the absence of any comparison of the wings-in and wings-out elements of the figure (as would occur with inspection of the Brentano version). However, the magnitude of the decrement effect observed here was not as pronounced as some

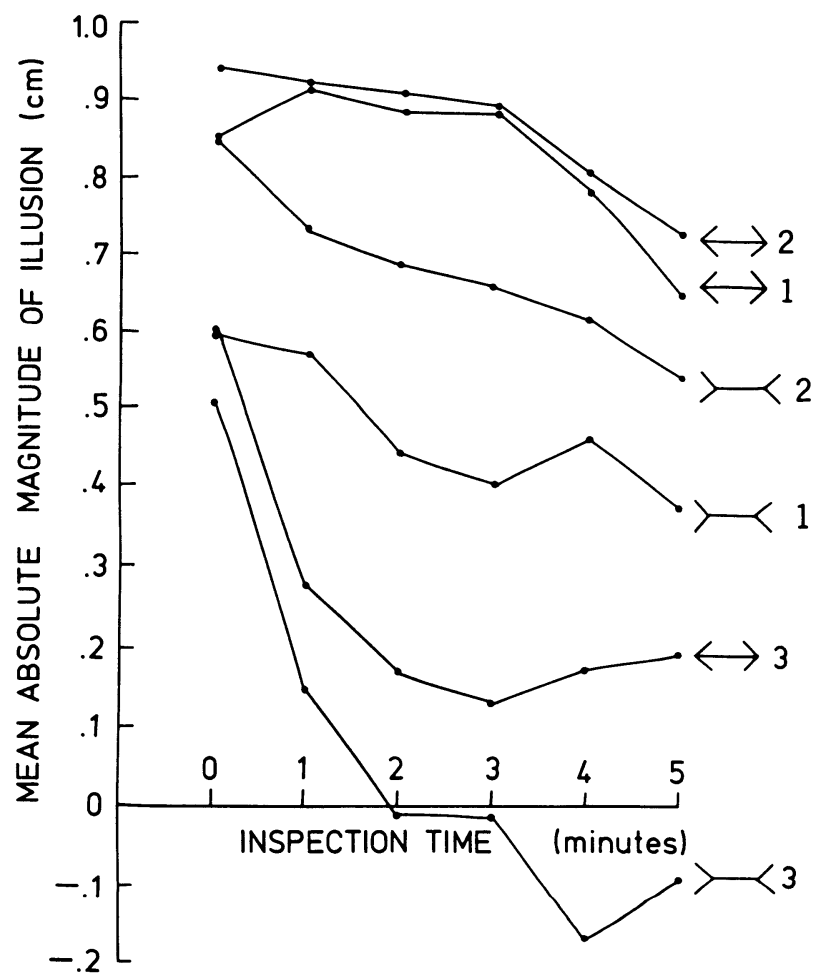

Figure 1. Mean absolute magnitude of the wings-in and wingsout Müller-Lyer illusion as a function of inspection time in Experiments 1,2 , and 3 . The number identifies the experiment from which the data originate. 
Table 1

Mean Absolute Magnitude of the Illusion (in $\mathrm{cm}$ ) and Standard Deviations as a Function of Inspection Time (in min)

\begin{tabular}{cccccc}
\hline \multirow{2}{*}{ Experiment } & \multirow{2}{*}{$\begin{array}{c}\text { Inspection } \\
\text { Time }\end{array}$} & \multicolumn{2}{c}{ Wings-in } & & \multicolumn{2}{c}{ Wings-out } \\
\cline { 3 - 5 } \cline { 5 - 6 } & $M$ & $S D$ & & $M$ & $S D$ \\
\hline 1 & 0 & .854 & .469 & .592 & .507 \\
& 1 & .913 & .510 & .572 & .581 \\
& 2 & .881 & .531 & .441 & .547 \\
& 3 & .880 & .425 & .406 & .603 \\
& 4 & .785 & .446 & .461 & .609 \\
2 & 5 & .644 & .415 & .372 & .517 \\
& 0 & .940 & .694 & .850 & .615 \\
& 1 & .916 & .601 & .734 & .624 \\
& 2 & .908 & .769 & .694 & .620 \\
& 3 & .890 & .687 & .662 & .676 \\
3 & 4 & .804 & .571 & .618 & .664 \\
& 5 & .732 & .668 & .536 & .564 \\
& 0 & .604 & .581 & .504 & .553 \\
& 1 & .274 & .494 & .143 & .713 \\
& 2 & .165 & .514 & -.013 & .612 \\
& 3 & .128 & .425 & -.019 & .576 \\
& 3 & .169 & .451 & -.169 & .593 \\
& 4 & .189 & .516 & -.093 & .607 \\
\hline
\end{tabular}

results reported by Coren and his colleagues with the use of the Brentano figure: For example, Coren and Girgus (1972) reported decrement effects of 55\%, and, more recently, decrement effects were reported to range from $25 \%$ to $50 \%$ (Coren \& Porac, 1984; Porac \& Coren, 1985).

Table 1 provides both the mean absolute magnitude of the wings-in and wings-out Müller-Lyer illusion as a function of inspection time and the standard deviation for each mean. The values clearly show that the variability of illusion response is high and does not decrease as a function of inspection time. In addition, it must be noted that a large number of subjects did not show a decrease in illusion magnitude. Specifically, an examination of each subject's data revealed that $29 \%$ (8 of 27 subjects) who inspected the wings-in figure showed no decrease in illusion magnitude when comparing preinspection (Time 0) judgments with judgments made after 5 min of inspection (Time 5). Similarly, 37\% (10 of 27 subjects) who inspected the wings-out figure showed no decrement.

Thus, the findings of the present experiment show moderate illusion decrement with high variability. It is of interest to note that most previous findings of illusion decrement do not report the variability associated with illusion decrement or the number of subjects who do not show illusion decrement. An exception to this comes from Day (1962), who also found a lack of uniformity among subjects who inspected the Brentano version of the MüllerLyer under a variety of conditions. Because other reports of illusion decrement have not provided information on variability and uniformity in subjects' responses, it is difficult to compare the present findings with other previous findings. However, it remains important to determine whether the moderate decrement effect observed here is comparable to conditions of no inspection. To address this question, Experiment 2 required subjects to make judg- ments at 1-min intervals without intervening periods of inspection of the Müller-Lyer figures.

\section{EXPERIMENT 2}

\begin{abstract}
Method
Subjects. Fifty undergraduate students served as subjects. All had corrected or uncorrected 20/20 vision.

Stimuli. Stimuli were series of Müller-Lyer figures identical to those used in Experiment 1. Inspection figures were not used.

Procedure. One group of 25 subjects made judgments on the wingsin figure; one group of 25 subjects made judgments on the wings-out figure.

Initially, each subject was presented with a stimulus sheet and instructed to indicate an estimate of the shaft length, as described in Experiment 1. After the subject's initial response, the stimulus sheet was placed in a folder. During an intervening period of $60 \mathrm{sec}$, the subject was asked simply to wait to make the next response. At the end of $60 \mathrm{sec}$, the subject was again given a stimulus sheet to judge. This process was repeated five times so that subjects made a total of six responses.
\end{abstract}

\section{Results and Discussion}

The extents produced by the subjects were measured to the nearest $0.5 \mathrm{~mm}$. Each response was then converted to a measure of the absolute magnitude of the illusion, as described in Experiment 1. The average absolute magnitude of the illusion over time, without inspection, is presented in Figure 1 for the wings-in and wings-out Müller-Lyer figures. The data from this experiment are labeled with the number 2 in the figure.

As before, homogeneity of variance was verified, and an analysis of variance was performed. The difference between wings-in and wings-out figures was not significant $[F(1,48)=1.392, p>.05]$. A significant decrement effect was found $[F(5,240)=3.599, p<.05]$. The interaction was not significant $[F(5,240)=.361$, $p>$.05].

Table 1 provides the mean illusion magnitude and standard deviation for the repeated judgments of Experiment 2. As in Experiment 1, variability in illusion response is high and does not decrease as a function of repeated judgments. Also similar to the findings of Experiment 1 is the percentages of subjects who did not show a decrease in illusion magnitude from the first response (Time 0) to the last response (Time 5). Twenty-eight percent of the subjects ( 7 of 25) who made repeated judgments on the wings-in figure did not show illusion decrement; $36 \%$ of the subjects (8 of 25 ) who made repeated judgments on the wings-out figure did not show a decrease in illusion magnitude.

The most critical result of this experiment is that the wings-in and wings-out Müller-Lyer illusions decrease without prolonged inspection. It is interesting to note that previous studies of Müller-Lyer decrement have not included this crucial control condition in their investigations.

It remains important to determine the conditions under which dramatic illusion-decrement effects occur with inspection of Müller-Lyer figures. One obvious difference between the method used in previous studies with the Brentano version and the present method is the inclusion of implicit feedback during inspection. Although other 
studies of illusion decrement with inspection of the Brentano version did not directly inform subjects of the extent of their errors, subjects did inspect a variation of the illusion in which wings-in and wings-out segments were set to physical equality. Corrective feedback information may be available to subjects under such inspection conditions. Therefore, our last experiment examined the role of implicit feedback during inspection.

\section{EXPERIMENT 3}

\section{Method}

Subjects. Forty-six undergraduate students served as subjects. All had corrected or uncorrected 20/20 vision.

Stimuli. Stimuli were series of standard Müller-Lyer figures identical to those used in Experiments 1 and 2. Inspection sheets contained the Müller-Lyer figure centered in the left half of the sheet and a 60 $\mathrm{mm}$ horizontal line centered in the right half of the sheet. Thus, inspection figures were identical to those used in Experiment 1 but included an inspection line equal to the shaft contained within the Müller-Lyer figure.

Procedure. Twenty-three subjects inspected and judged the wingsin Müller-Lyer figure; 23 subjects inspected and judged the wings-out version. During inspection, the subjects were instructed to move their eyes back and forth across the entire inspection sheet and were informed at the beginning of each inspection period that the central shaft length of the figure on the left was equal to the line length on the right. All other procedures were previously described in Experiment 1.

\section{Results and Discussion}

The extents produced by the subjects were measured to the nearest $0.5 \mathrm{~mm}$ and converted to measures of the absolute magnitude of the illusion, as described in Experiment 1 . The mean absolute magnitude of the wingsin and wings-out Müller-Lyer illusion as a function of inspection time is presented in Figure 1. The data from this experiment are labeled with the number 3 in the figure.

Homogeneity of variance was verified and an analysis of variance was performed, as in Experiments 1 and 2. No significant difference was found between wings-in and wings-out figures $[F(1,44)=2.212, p>.05]$. A significant decrement effect was found $[F(5,220)=14.780$, $p<.001]$. The interaction was not significant $[F(5,220)$ $=.762, p>.05]$.

As before, Table 1 provides both the mean illusion magnitude as a function of inspection time and the standard deviation associated with each value. It is interesting to note that the variability observed in Experiment 3 is comparable to that observed in Experiments 1 and 2. Additionally, a large percentage of subjects did not show a decrease in illusion magnitude, even when they were provided implicit feedback during inspection: $21 \%$ of the subjects ( 5 of 23 ) who inspected the wings-in figure showed no decrease in illusion magnitude after $5 \mathrm{~min}$ of inspection, and $17 \%$ of the subjects (4 of 23 ) who inspected the wings-out figure showed no decrease in illusion magnitude after $5 \mathrm{~min}$ of inspection.

The results of this experiment suggest that dramatic illusion decrement can be obtained when subjects are provided with implicit feedback during periods of inspection. However, even when the conditions of inspection include implicit feedback, and thus are made more comparable to previous studies of illusion decrement that used the Brentano version, the variability associated with illusion responses is high, and some subjects do not show a decrease in illusion magnitude after $5 \mathrm{~min}$ of inspection.

\section{GENERAL DISCUSSION}

The findings of our experiments can be summarized briefly, as follows. Separate inspection of the wings-in and wings-out Müller-Lyer figures does not produce different decrement effects. Illusion decrement occurs even in the absence of a comparison between wings-in and wingsout figures. However, comparable illusion decrement also occurs under the control condition of repeated judgments of the wings-in and wingsout figures without concentrated inspection between judgments. Thus, one wonders whether the decrease in the magnitude of the illusion observed in Experiment 1 can be considered a genuine illusion-decrement effect. When the subjects were provided with comparison information that contained implicit feedback during inspection, pronounced illusion decrement was obtained. The variability associated with judgments of illusion figures under all conditions of inspection examined here was high, and a large percentage of the subjects did not show a decrease in illusion magnitude even after $5 \mathrm{~min}$ of inspection.

In general, caution needs to be exercised in drawing conclusions about illusion decrement with inspection of the Müller-Lyer illusion, given the high variability in subjects' responses and the large number of subjects who do not show illusion decrement. The present results are consistent with those reported by Day (1962), who examined illusion decrement with the Brentano version of the Müller-Lyer illusion under several conditions of inspection. It is plausible that individual differences in illusion responses (see, e.g., Coren \& Porac, 1987) may be the most critical factor in obtaining illusion decrement.

\section{REFERENCES}

Coren, S., \& Girgus, J. S. (1972). Illusion decrement in intersecting line figures. Psychonomic Science, 26, 108-110.

COREN, S., PorAC, C. (1984). Structural and cognitive components in the Müller-Lyer illusion assessed via Cyclopean presentation. Perception \& Psychophysics, 35, 313-318.

CoRen, S., \& PorAc, C. (1987). Individual differences in visualgeometric illusions: Predictions from measures of spatial cognitive abilities. Perception \& Psychophysics, 41, 211-219.

DAY, R. H. (1962). The effects of repeated trials and prolonged fixation on error in the Müller-Lyer figure. Psychological Monographs, 76, 1-19.

Festinger, L., White, C. W., Allyn, M. R. (1968). Eye movements and decrement in the Müller-Lyer illusion. Perception \& Psychophysics, 3, 376-382.

Girgus, J. S., \& CoRen, S. (1973). Peripheral and central components in the formation of visual illusions. American Journal of Optometry \& Archives of the American Optometry Society, 50, 533-540.

Girgus, J. S., Conen, S., Horowitz, L. (1973). Peripheral and central components in variants of the Mueller-Lyer illusion. Perception \& Psychophysics, 13, 157-160.

Greist-Bousquet, S., SChiffMan, H. R. (1981). The role of structural components in the Mueller-Lyer illusion. Perception \& Psychophysics, 30, 505-511.

Kohler, W., Fishback, J. (1950). The destruction of the MüllerLyer illusion in repeated trials: I. An examination of two theories. Journal of Experimental Psychology, 40, 267-281.

Porac, C., \& CoRen, S. (1985). Transfer of illusion decrement: The effects of global versus local figural variations. Perception \& Psychophysics, 37, 515-522.

(Manuscript received September 7, 1990.) 